\title{
Update on Biomarkers to Monitor Clinical Efficacy Response During and Post Treatment in Allergen Immunotherapy
}

Lubna Kouser, $P h D^{1}$

Jasper Kappen, MD, MSc, $P h D^{1,2}$

Ross P. Walton, $P h D^{3}$

Mohamed H. Shamji, MSc, PhD, FAAAAI ${ }^{1, *}$

\begin{abstract}
Address
${ }^{*}, 1$ Immunomodulation and Tolerance Group, Allergy and Clinical Immunology, Inflammation, Repair and Development, Faculty of Medicine, Imperial College London, National Heart and Lung Institute, London, SW7 2AZ, UK

Email:m.shamji@imperial.ac.uk

${ }^{2}$ Department of Pulmonology, STZ centre of excellence for Asthma \& COPD, Sint Franciscus Vlietland group, Kleiweg 500, 3045 PM, Rotterdam, The Netherlands

${ }^{3}$ Airway Disease Infection Section, Imperial College London, part of the Medical Research Council and Asthma UK Centre for Allergic Mechanisms of Asthma, St. Mary's Hospital, National Heart and Lung Institute (NHLI), London, W2 1PG, UK
\end{abstract}

Published online: 10 March 2017

(C) The Author(s) 2017. This article is published with open access at Springerlink.com

This article is part of the Topical Collection on Specific Immunotherapy

Lubna Kouser equally contributed to this work

Keywords Allergen immunotherapy · Tregs · ILC2 • Biomarkers • IgG4 • AIT

\section{Opinion statement}

Allergen immunotherapy (AIT) is an immune modulating treatment for allergic diseases. Although highly effective, some patients do not respond to the treatment. To date there are no surrogate biomarkers that are predictive of the clinical response to AIT. More and more is known about the underlying immunological mechanism involved in AIT. Through modulation of both innate and adaptive immune responses, involving reduced ILC2 and enhanced Treg and Breg induction and functionality, along with induction of IgG4 antibody production which have the capacity to inhibit both allergen-induced basophil responsiveness and CD23mediated IgE-facilitated allergen presentation, the result is an immune skewing towards a more balanced Type I response. So far, however there is not a clear correlation with the observed immunological changes and predictive correlates of clinical efficacy. The most 
promising biomarker of successful AIT is IgE-FAB as a reflection of functional IgG4. Cellular responses and cytokine analysis gives a great deal of insight into the mechanisms of AIT but may not represent useful or indeed reliable biomarkers in a clinical setting. There is a need for more research for confirmation and interpretation of the possible association with biomarkers and clinical response to AIT.

\section{Introduction}

Allergen immunotherapy (AIT) is the only disease-modifying therapy available for IgE-mediated diseases such as allergic rhinitis, allergic asthma and atopic dermatitis[1, 2]. AIT is a safe and effective treatment indicated only in those patients whose symptoms are mostly uncontrolled by conventional pharmacotherapy such as antihistamines or nasal steroids $[3,4]$. AIT, which can be administered either subcutaneously (SCIT) or sublingually (SLIT), reduces both symptoms and the need of rescue medication [5-7], improves patient's quality of life [8] and confers long-term clinical benefits after cessation of treatment $[9,10 \bullet \bullet, 11,12,13 \bullet]$. Although AIT is effective, the degree of remission depends on several unidentified factors $(1,6,13 \bullet, 14-17)$. It is therefore, essential to determine biomarkers that would: identify those patients most likely to respond to therapy; indicate when to stop treatment; predict symptomatic relapse and inform on when to perform a booster AIT. Application of such knowledge, would undoubtedly contribute to the use of biomarkers of AIT in personalised medicine [18]. Novel insight in to the mechanism which govern AIT is essential for the identification of robust biomarkers. This review presents an updated overview of the underlying mechanism and novel potential biomarkers of AIT.

\section{Mechanisms of AIT}

\section{Immunomodulation of ILC2s and IL $13^{+}$ILC2s by AIT}

Innate lymphoid cells (ILCs) are morphologically similar to lymphocytes but lack the rearranging antigen receptors [32]. ILCs can be grouped into three known subsets: ILC1, ILC2, and ILC3 (Fig. 1), which is defined by a 

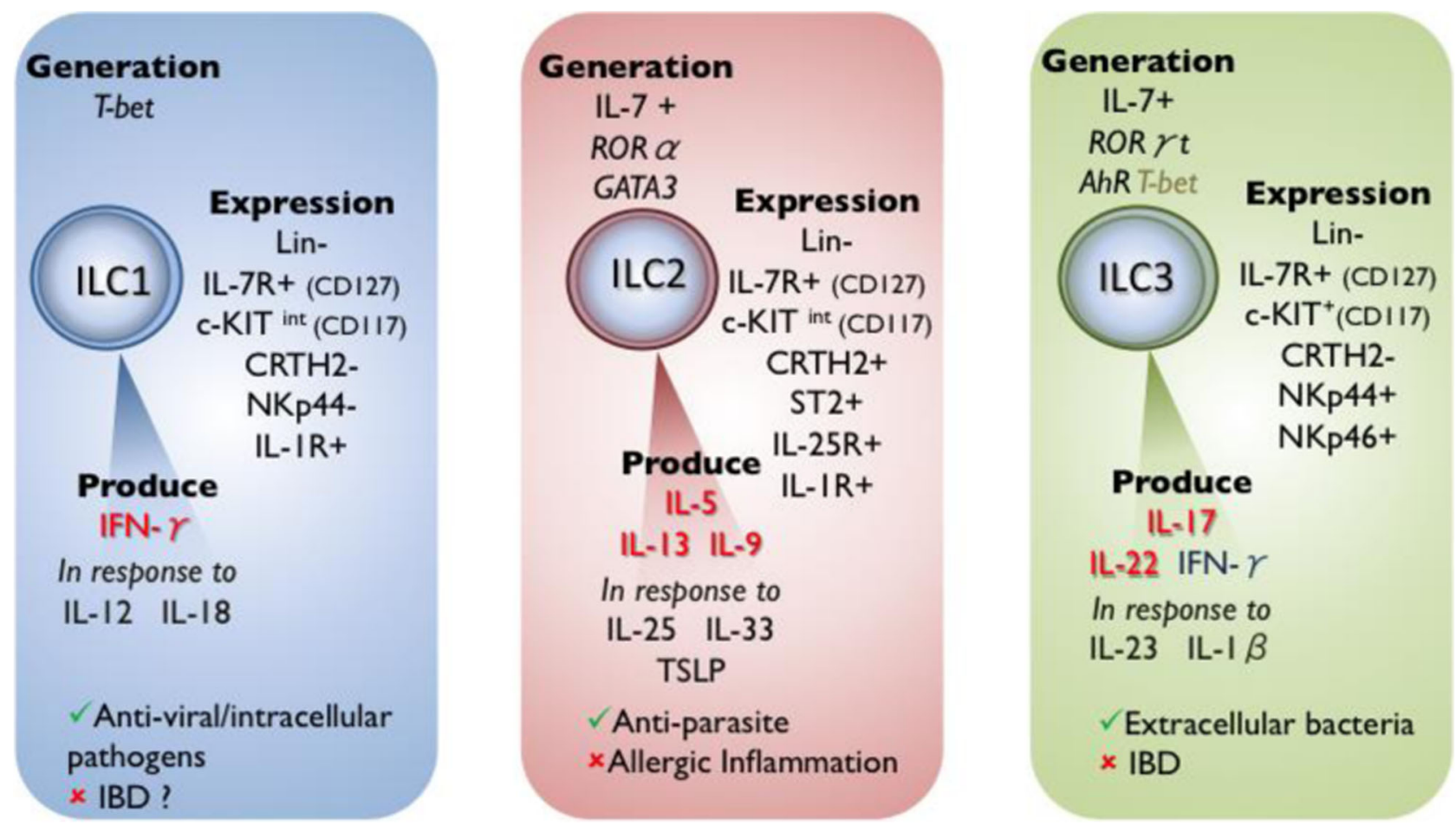

Fig. 1. Innate lymphoid cells. Three groups of non-cytotoxic lineage negative ILCs are defined as ILC1, ILC2, and ILC3. ILCs express the subunits of cytokine receptors such as interleukin (IL)-2 receptor- $\alpha$ (CD25) and IL-7 receptor- $\alpha$ (CD127) but do not express the somatically rearranged antigen receptors as $T$ and $B$ cells and lack antigen specificity. Thus exhibit functions in an antigenindependent manner. ILC1s produce IFN- $\gamma$ in response to IL-12 and IL-18 providing immunity to intracellular bacteria and parasites. Whereas ILC2s are stimulated by IL-25, IL-33, or TSLP to produce Th2 cytokines such as IL-5, IL-13, and IL-9 causing allergic inflammation. ILC2s also provide immunity to helminths as well as tissue repair. The ILC3s are driven by IL-23, IL-1 $\beta$ to produce IL17, IL-22, and IFN- $y$, which promote immunity to extracellular bacteria and tissue repair.

combination of surface markers, transcription factors that are critical for their generation, and cytokines that they produce [33].

In particular, ILC2 effector function is driven by epithelial derived mediators IL33 [34], IL-25 [35], TSLP [36], as well as leukotriene D4 to produce Th2 cytokines such as IL-4, IL-5, IL-9, and IL-13 [33]. ILC2s promote type 2 allergic inflammation, and tissue repair [33]. First described in mouse, an analogous population of ILC2 was identified in human skin, revealing a population of $\mathrm{Lin}^{-} \mathrm{CD} 25^{+} \mathrm{ST} 2^{+} \mathrm{c}-\mathrm{Kit}^{+}$ $\mathrm{CD}_{127^{+}} \mathrm{ICOS}^{+}$which did not express markers of ILC3, CD4, NKp46, and ROR $\mathrm{t}$ [36]. Shortly after, the presence of ILC2s, which shared the same morphology as those in the skin, was confirmed in other organs [37]. Skin-specific expression of IL33 in transgenic mice was associated with atopic dermatitis like cutaneous appearance. These mice had increased levels of $\mathrm{Lin}^{-} \mathrm{ST}_{2}^{+} \mathrm{Sca}-1^{+} \mathrm{ILC} 2 \mathrm{~s}$ in the skin lesions, peripheral blood, and regional lymph nodes. $\mathrm{Lin}^{-} \mathrm{ST} 2^{+} \mathrm{Sca}-1^{+}$produced IL-5 and IL-13 in response to IL-33 compared to wild-type mice that did not produce this effect in the lymph nodes, suggesting that IL-33 stimulates ILC2s [34]. However, Kim and Colleagues [36] reported that the ILC2s were induced by TSLP in an IL-33 independent manner. It was further elucidated that the response of ILC2s to TSLP, IL-25, or IL-33 regulated skin inflammation. High levels of ILC2s were found in the skin of atopic dermatitis with the elevated expression of IL-17RB (IL-25R), ST2 
(IL-33R), and TSLP receptors. The increased expression was associated with elevated levels of IL-25 and IL-33 expression. BALB/C strain mice deficient in cytokine receptors for IL-33, IL-25, and TSLP had decreased skin inflammation of ear tissue and skin-draining lymph nodes; however in response to TSLP, the reduction in skin inflammation was moderate. These findings confirmed these cytokines are involved in the regulation of ILC2s in the pathogenesis of atopic dermatitis, an IgEmediated disease [37].

The relevance of ILC2s to the pathophysiology of allergic rhinitis was firstly demonstrated in subjects who underwent intranasal cat allergen provocation [38•]. Nasal cat allergen challenge resulted in an increase of peripheral blood ILC2s expressing CD84. Diluent challenge resulted in no change in the percentage of ILC2s whereas the levels of ILC2s were promptly elevated after $4 \mathrm{~h}$ when challenged with cat allergen. These findings indicated that acute induction of ILC2s could play a role in the pathogenesis of allergic rhinitis [38•]. Moreover, peripheral blood $\mathrm{CD} 117^{+} \mathrm{ILC} 2 \mathrm{~s}$ and IL-13 $3^{+} \mathrm{ILC} 2 \mathrm{~s}$ have been shown to be increased in grass pollen allergic individuals with seasonal allergic rhinitis following natural grass pollen allergen exposure during the pollen season compared to out of the pollen season [23••]. Grass pollen SCIT blunted the seasonal increases of CD117 ILC2s as well as IL-13 ${ }^{+}$ILC2s $[23 \bullet \bullet]$. Interestingly, the proportion of ILC2 correlated with visual

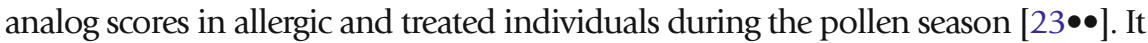
is important to note that outside the pollen season, the frequency of CD $117^{+} \mathrm{ILC} 2 \mathrm{~s}$ and IL-13 ${ }^{+}$ILC2s between grass pollen allergics and non-allergic controls remained unaltered $[23 \bullet \bullet]$. These findings were confirmed by recent reports that demonstrated that the number of ILC2s found in the peripheral blood of allergic subjects were similar to the non-allergics [39]. However, allergic asthmatics had elevated numbers of ILC2s and ILC3s in the periphery. This study also confirmed that the frequency of ILC2s and ILC3s were high during the grass pollen season in those that were sensitized to grass pollen allergen. In addition, a short 4-month SLIT did not reduce the frequency of ILC2s. It is likely that the discrepancy of findings between the SCIT and SLIT study was due to the enumeration of ILC2s in active and placebo groups being conducted outside of the pollen season [39]. More studies are needed to evaluate the effect of AIT on ILC2s and whether there is a relationship between ILC2s and clinical response to AIT.

\section{Molecular markers of DCs as biomarkers AIT success}

Dendritic cells are the key orchestrators of both the innate and the adaptive immune responses, one aspect of which includes regulation of $\mathrm{T}$ cell responses. When triggered by an allergen, immature DCs polarize into DC1s, DC2s, DC17s, or DCregs, which in turn can differentiate T cells into Th1 cells (DC1s), Th2 cells (DC2s), Th17 cells (DC17s), or regulatory

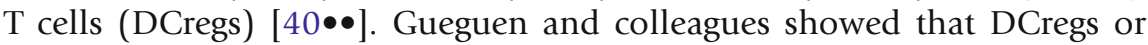
tolerogenic DCs were generated when DCs were exposed to dexamethasone (DEX), which resulted in an increased expression of Ig-like transcript 2 (ILT2) and Ig-like transcript 4 (ILT4). Co-culture of tolerogenic DCs with $\mathrm{CD} 4^{+} \mathrm{T}$ cells resulted in upregulation of IL-10 but not Foxp3. Moreover, DC1 and DC17 effector DC markers such as CD71, FSCN1, IRF4, NMES1, MX1, and TRAF1 were significantly upregulated. Interestingly, tolerogenic DC markers were associated with ANXA1, complement component 1 
(C1Q), CATC, GILZ, F13A, FKBP5, Stabilin-1 (STAB1), and TPP1 molecules. ANXA1 and FKBP5 were overexpressed in regulatory DCs. The expression of C1Q A, B, and C, as well as STAB1 was increased in peripheral blood of monocyte derived tolerogenic DCs in subjects of who received sublingual grass pollen immunotherapy. C1QA, C1QB, C1QC, and STAB1 were also found to be upregulated in patients with confirmed clinical response to treatment. The $\mathrm{C} 1 \mathrm{Q}$ and STAB1 expression was consistently induced in response to treatment and also correlated with clinical benefit in SLIT-treated patients [41]. Gueguen and colleagues identified additional molecular markers that are differentially regulated in DC2s and DCregs, evaluated their role as predictive biomarkers of efficacy. Changes in expression of 5 combined DCreg/DC2-associated markers in PBMCS correlated with clinical efficacy of SLIT at 2 and 4 months. Interestingly, the four markers of DC2 cells (CD141, GATA3, OX40L, and RIPK4) were decreased after 4 months of AIT in allergic rhinitis patients, whereas the expression of 4 DCreg cell markers (i.e., C1QA, FceRIIIA, FTL, and SLCO2B1) were increased in the peripheral blood of allergic rhinitics. This implies that AIT stimulates the expression of markers for DC2 and DCreg

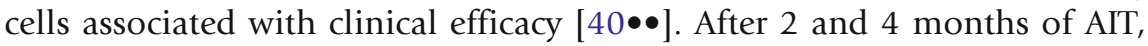
the optimal combination of five molecular markers of which three DC2 (CD141, GATA3, and RIPK4) and two DCreg (C1QA and Fc $\gamma$ RIIIA) resulted in effective classification of clinical responders from non-responders. The combined markers had a sensitivity of $90.48 \%$ and a specificity of $61.9 \%$. Although, these findings were very interesting, they need to be validated in large clinical studies of SCIT, SLIT and then in clinical practice.

\section{T cell responses and AIT}

Inflammatory responses in allergic diseases are widely considered to be Th2 mediated. Th2 cytokines such as IL-4, IL-5, and IL-13 subsequently are responsible for the induction of effector cells [42]. The production of specific IgE by B cells is also facilitated by Th2. AIT is associated with immune deviation from Th2 to Th1 responses and induction of regulatory $\mathrm{T}$ cells. Regulatory $\mathrm{T}$ cells (Tregs) modulate the immune response, mediate immune tolerance, and prevent autoimmune diseases [43]. A substantial body of evidence also suggests that Tregs play an important role in the control of allergy. AIT can drive the immune response towards induction of Treg cells resulting increased IL-10 and TGF- $\beta$ production and suppression of IgE production [30]. During AIT, the number of Th2 memory cells is reduced with an induced Treg/Th1 response [44]. Treg cells can be induced through high-dose allergen exposure, such as multiple stings received by beekeepers and prolonged, domestic cat-allergen exposure which have been demonstrated to induce IL-10-mediated tolerance and increased levels of antigen-specific IgG4. Furthermore, T cells producing IL10 as well as Foxp $3^{+} \mathrm{IL}-10^{+} \mathrm{T}$ cells were shown to be increased in nasal mucosa of immunotherapy patients one [45]. IL-10 has an important role in the control of allergy by suppressing allergic inflammation and inducing regulatory $\mathrm{T}$ cells. The balance between allergen-specific $\mathrm{T}$ cell subsets may be influenced by AIT, as Tr1 cells have been found to be reduced in 
peripheral blood for atopic patients but increased in AIT treated patients [25•]. To summarize, Tregs appear to play an essential role in the induction of tolerance in AIT suppressing the allergic Th2 response and inducing the more tolerant Th1 state. Identifying their true relationship to clinical response remains to be investigated.

\section{B regulatory cells and immune tolerance}

Regulatory B cells (Bregs) are a subset of CD19+ B cells that produce IL-10 and have the capacity to supress pro-inflammatory $\mathrm{T}$ and $\mathrm{B}$ cell effector function. Bregs promote immune tolerance state through production of interleukin-10 (IL-10), IL-35 and transforming growth factor b (TGF- $\beta$ ). IL-10-producing B cells have been most extensively studied for their regulatory potential in man and mice. To date, IL$10^{+} \mathrm{B}$ cells have been reported to reside within $\mathrm{CD} 1 \mathrm{~d}^{\text {hi }} \mathrm{CD} 5^{+}, \mathrm{CD} 24^{\mathrm{hi}} \mathrm{CD} 27^{+}$,

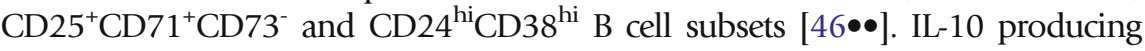
$\mathrm{CD} 25^{+} \mathrm{CD} 71^{+} \mathrm{CD} 73^{-}$Breg subset has been shown to be induced following AIT. They regulate pro-allergic immune responses by inhibiting antigen-specific $\mathrm{CD} 4^{+} \mathrm{T}$

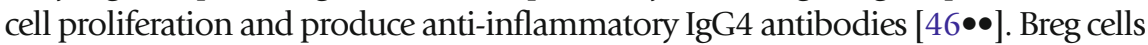
control excessive inflammatory responses through IL-10 secretion, and are involved in Treg cells differentiation by inhibiting release of proinflammatory cytokines [47•]. In bee-venom, tolerant individual, highly purified IL-10-secreting Breg cells were phenotypically characterized via high expression of surface CD25 and CD71 level but low level of CD73 (Human BR1 cells, CD73-CD25 ${ }^{+} \mathrm{CD} 71^{+}$B cells)

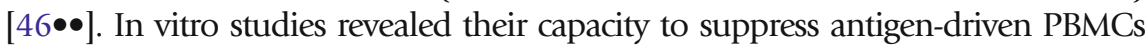
proliferation. In the same study, bee-venom allergen (PLA2)-specific CD19 $9^{+}$B cells were increased following bee-venom AIT and produced IL-10 [46••].

\section{Functional IgG4 antibodies as potential biomarkers of AIT}

An immunologic response following administration of large doses of the sensitizing allergen either by SCIT or SLIT has been associated with the induction of serum allergen-specific immune reactive and functional IgG antibodies (sIgG). A 10-100fold increase in the concentrations of allergen-specific IgG1 and, in particularly of IgG4 antibodies has been reported in several SCIT and SLIT studies [48, 49]. A correlation between serum allergen-specific IgG4 and clinical outcome measures have been explored in some but not all studies [5053]. In a dose-response randomized double-blind placebo-controlled trial (RDBPCT) of SCIT, levels of sIgG4 were increased in a time- and dosedependent manner [16••]. Conversely, allergen-IgE binding to B cells was decreased in a time- and dose-dependent manner. The serum inhibitory activity for IgE-FAB but not serum IgG4 correlated with combined symptoms and rescue medication scores (CSMS) at the population level but not at the individual level $[16,54 \bullet]$. Furthermore, in a SCIT withdrawal study where participants were randomized to receive grass pollen-SCIT or placebo for 2 years, the actively treated group were further randomized to receive either placebo injections or SCIT for further 2 years. During treatment, the levels of sIgG1 and sIgG4 were shown to be increased at 2 years and at 4 years in the actively treated group. Those who received active treatment for 2 years and 2 years of placebo had increased levels of sIgG1 and sIgG4 at 2 years which declined (near 80\%) at 


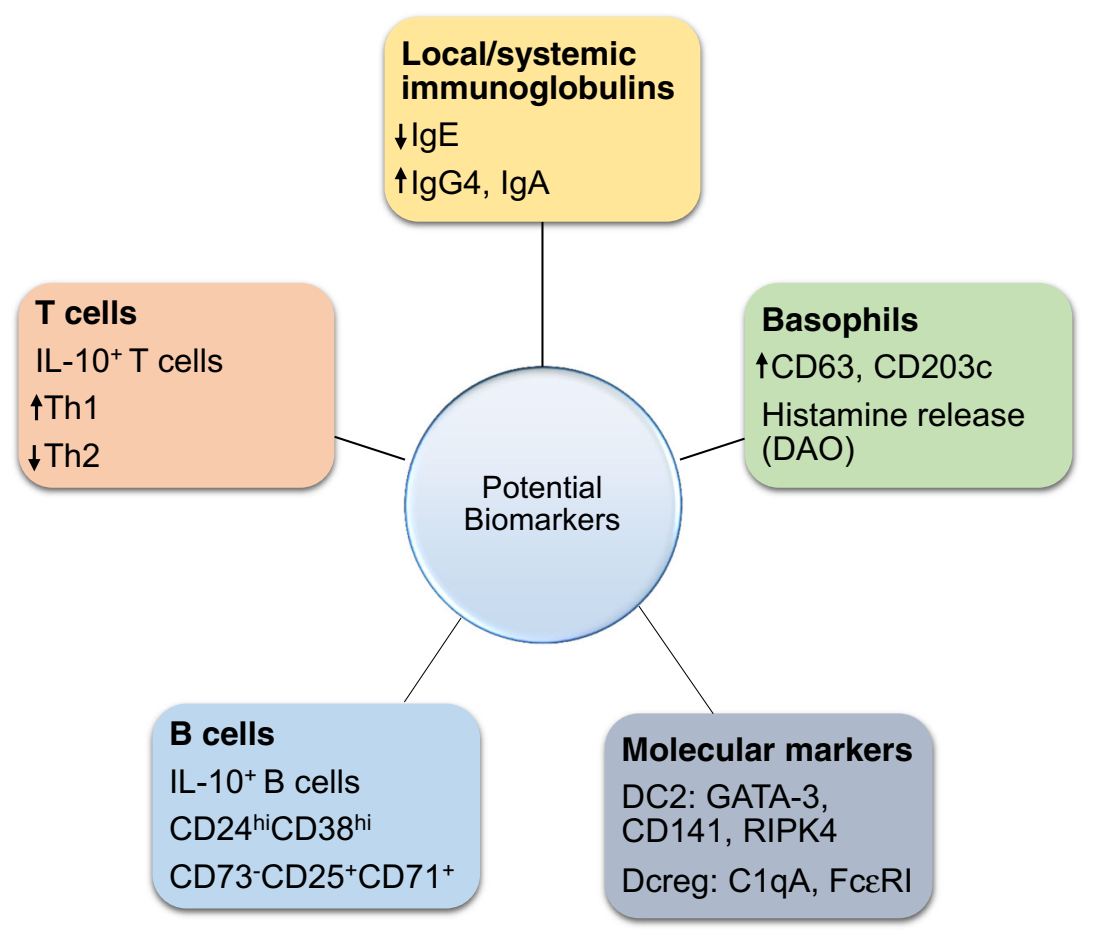

Fig. 2. Biomarkers associated with allergen response and AIT. Biomarkers for various cell types may exhibit clinical benefit for allergen immunotherapy. The conventional T cell response to allergen mediating a $\mathrm{CD}^{+} \mathrm{T}$ cell response has been widely evaluated. The increase of $\mathrm{CD}^{+}$T cells in response to allergen elicits a Th2 cytokine storm such as IL-4, IL-5, and IL-13 causing an allergic response or asthma. On the other hand, Tregs have a protective role in allergy as they modulate immune tolerance to allergen and control the allergic reaction during allergen immunotherapy. AIT deviates the immune response towards Tregs increasing the IL-10 and TGF- $\beta$ production with a decrease in IgE, whereas the elevated IgG 4 as well as IgA is mediated by B cells. The increase in Treg subsets Foxp $3^{+}$and $\operatorname{Tr} 1$ are also induced by AIT may be important biomarkers post-immunotherapy. The immune response can become resistant to immune deviation to Tregs/Th1 subsets; $C_{4} 4^{+} T$ cells (CD27-) expressing CRTH2 also produce a Th2 response. The CD27 (Th2) subset have been found to be decreased in AIT treated subjects, whereas the protective $\mathrm{CD}^{-} 7^{+}$(Th2) subset was elevated. Additionally, IL10+ Bregs can induce protective IgG4 response and inhibit the antigen-specific $\mathrm{CD} 4^{+} \mathrm{T}$ cell proliferation during AIT. Furthermore, the DC markers in response to immunotherapy have an increased DCreg (C1QA and FCERIIIA) and decreased DC2 (GATA-3, CD141, and RIPK4) response. A novel biomarker for basophils has also been established intracellular expression of fluorochrome-labeled diamine oxidase, which was increased in SAR patients but reduced during SCIT and SLIT. The reduction in histamine, CD63, and CD203c by basophils was also associated with reduced symptoms.

4 years (2-year off treatment). Interestingly, serum inhibitory activity for IgEfacilitated allergen binding persisted 2 years after discontinuation of treatment. IgG4 depleted sera from patients who have discontinued immunotherapy showed reduction in the inhibitory activity of allergen-IgE binding. These findings indicate that functional and protective antibody responses is critical for long-term clinical tolerance $[55 \bullet \bullet]$.

\section{Basophils and clinical responses to AIT}

Basophils were originally identified by Paul Ehrlich in 1879 . They comprise of $<1 \%$ human leukocytes in peripheral blood. They contain cytoplasmic secretory granules, consisting of proteoglycans and histamine [56]. Basophils express 


\title{
Concluding remarks
}

FceRI, which can be cross-linked by allergen-specific IgE after allergen exposure, resulting in degranulation with release of histamine, leukotrienes, and other mediators of the allergic inflammatory response $[57,58]$. Surface expression of CD63 (granule-associated tetraspan) is typically detected on allergen-stimulated and activated basophils in whole blood, whereas CD203c is expressed on nearly all basophils regardless of their activation status. CD63 and CD203c (ectonucleotide pyrophosphatase/phospodiesterase 3, a type II transmembrane ectoenzyme) are complementary for assessing basophil activation [59, 60•]. Basophil also express multiple membrane proteins including CD13, CD107a, and CD164 which are expressed when activated. Furthermore, histamine can be measured in bronchoalveolar lavage fluid from those with allergic asthma and in plasma of atopic dermatitis patients [61]. More recently, intracellular expression of fluorochrome-labeled diamine oxidase (DAO) in basophils has been reported

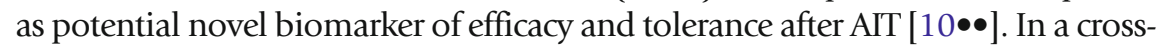
sectional study of AIT, basophil activation induced by grass pollen allergen was elevated in seasonal allergic rhinitis (SAR) patients and diminished in SCIT or SLIT treated individuals. The reduction in basophil responsiveness and histamine release as measured by DAO using flow cytometry was associated with reduced combined symptoms and rescue medication scores $[10 \bullet \bullet]$.

\begin{abstract}
Our current understanding of the application of AIT has highlighted a series of
possible immunological biomarkers which can be utilized to determine efficacy of treatment efficacy (Fig. 2). It is known that both innate and adaptive immune responses are modulated during AIT. The reduction of ILC2s in combination with Tregs and Bregs result in skewing towards a Th1. IgG4 antibodies have the capacity to inhibit both allergen-induced basophil responsiveness and CD23mediated IgE-facilitated allergen presentation. Although these changes are observed repeatedly after AIT, identifying their true relationship to clinical response remains to be investigated before they can be applicable as surrogate biomarkers. Functional IgG4, represented by IgE-FAB, however, appears to be a promising biomarker with correlation with clinical outcome as well as tolerance. Molecular markers identified in DC2 (CD141, GATA3, and RIPK4) and DCreg (C1QA and Fc $\gamma$ RIIIA) induced by AIT are crucial emerging biomarkers for clinical response. There is an urgent need for studies correlating the knowledge on immunological changes in AIT before biomarkers can play a role in personalized medicine.
\end{abstract}

\section{Compliance with Ethical Standards}

\section{Conflict of Interest}

Dr. Lubna Kouser, Dr. Jasper Kappen, Dr. Ross P. Walton, and Dr. Mohamed H. Shamji declare that they have no conflicts of interest.

Human and Animal Rights and Informed Consent

This article does not contain any studies with human or animal subjects performed by any of the authors. 
Open Access This article is distributed under the terms of the Creative Commons Attribution 4.0 International License (http://creativecommons.org/licenses/by/4.0/), which permits unrestricted use, distribution, and reproduction in any medium, provided you give appropriate credit to the original author(s) and the source, provide a link to the Creative Commons license, and indicate if changes were made.

\section{References and Recommended Reading}

Papers of particular interest, published recently, have been highlighted as:

- Of importance

- Of major importance

1. Bousquet J, Lockey R, Malling HJ. Allergen immunotherapy: therapeutic vaccines for allergic diseases. A WHO position paper. J Allergy Clin Immunol. 1998;102(4 Pt 1):558-62.

2. Bousquet J, Lockey R, Malling HJ, Alvarez-Cuesta E, Canonica GW, Chapman MD, et al. Allergen immunotherapy: therapeutic vaccines for allergic diseases. World Health Organization. American academy of Allergy, Asthma and Immunology. Ann Allergy Asthma Immunol. 1998;81(5):401-5.

3. Cox L, Nelson H, Lockey R, Calabria C, Chacko T, Finegold I, et al. Allergen immunotherapy: a practice parameter third update. J Allergy Clin Immunol. 2011;127(1 Suppl):S1-55.

4. Bousquet J, Schunemann HJ, Samolinski B, Demoly P, Baena-Cagnani CE, Bachert $\mathrm{C}$, et al. Allergic Rhinitis and its Impact on Asthma (ARIA): achievements in 10 years and future needs. J Allergy Clin Immunol. 2012;130(5):1049-62.

5. Calderon MA, Penagos M, Sheikh A, Canonica GW, Durham S. Sublingual immunotherapy for treating allergic conjunctivitis. Cochrane Database Syst Rev. 2011;7:CD007685.

6. Calderon MA, Alves B, Jacobson M, Hurwitz B, Sheikh A, Durham S. Allergen injection immunotherapy for seasonal allergic rhinitis. Cochrane Database Syst Rev. 2007; 1:CD001936.

7. Compalati E, Braido F, Canonica GW. An update on allergen immunotherapy and asthma. Curr Opin Pulm Med. 2014;20(1):109-17.

8. Powell RJ, Frew AJ, Corrigan CJ, Durham SR. Effect of grass pollen immunotherapy with Alutard SQ on quality of life in seasonal allergic rhinoconjunctivitis. Allergy. 2007;62(11):1335-8.

9. Demoly P, Okamoto Y, Yang WH, Devillier P, Bergmann KC. 300 IR HDM tablet: a sublingual immunotherapy tablet for the treatment of house dust mite-associated allergic rhinitis. Expert Rev Clin Immunol. 2016;12(11):1141-51.

10.• Shamji MH, Layhadi JA, Scadding GW, Cheung DK, Calderon MA, Turka LA, et al. Basophil expression of diamine oxidase: a novel biomarker of allergen immunotherapy response. J Allergy Clin Immunol. 2015;135(4):913-21 e9.

The allergen immuntherapy and biomarker field.

11. Aasbjerg K, Backer V, Lund G, Holm J, Nielsen NC, Holse $\mathrm{M}$, et al. Immunological comparison of allergen immunotherapy tablet treatment and subcutaneous immunotherapy against grass allergy. Clin Exp Allergy. 2014;44(3):417-28.

12. Eifan AO, Akkoc T, Yildiz A, Keles S, Ozdemir C, Bahceciler NN, et al. Clinical efficacy and immunological mechanisms of sublingual and subcutaneous immunotherapy in asthmatic/rhinitis children sensitized to house dust mite: an open randomized controlled trial. Clin Exp Allergy. 2010;40(6):922-32.

13. Durham SR, Walker SM, Varga EM, Jacobson MR, $\mathrm{O}^{\prime}$ Brien F, Noble W, et al. Long-term clinical efficacy of grass-pollen immunotherapy. N Engl J Med. 1999;341(7):468-75.

The allergen immuntherapy and biomarker field.

14. Bousquet J, Van Cauwenberge P, Khaltaev N, Aria Workshop G, World Health O. Allergic rhinitis and its impact on asthma. The Journal of allergy and clinical immunology. 2001;108(5 Suppl):S147-334.

15. Bousquet J, Khaltaev N, Cruz AA, Denburg J, Fokkens WJ, Togias A, et al. Allergic Rhinitis and its Impact on Asthma (ARIA) 2008 update (in collaboration with the World Health Organization, GA(2)LEN and AllerGen). Allergy. 2008;63(Suppl 86):8-160.

16.• Shamji MH, Ljorring C, Francis JN, Calderon MA, Larche M, Kimber I, et al. Functional rather than immunoreactive levels of IgG4 correlate closely with clinical response to grass pollen immunotherapy. Allergy. 2012;67(2):217-26.

The allergen immuntherapy and biomarker field.

17. Radulovic S, Calderon MA, Wilson D, Durham S. Sublingual immunotherapy for allergic rhinitis. Cochrane Database Syst Rev. 2010;12:CD002893.

18. Galli SJ. Toward precision medicine and health: Opportunities and challenges in allergic diseases. J Allergy Clin Immunol. 2016;137(5):1289-300.

19. Kawabori S, Nakamura A, Okude Y. The reactivity of mast cells in nasal mucosa:-comparison between allergic and nonallergic disease. Auris Nasus Larynx. 1987;14(2):77-86.

20. Nouri-Aria KT, Wachholz PA, Francis JN, Jacobson MR, Walker SM, Wilcock LK, et al. Grass pollen immunotherapy induces mucosal and peripheral IL-10 responses and blocking IgG activity. J Immunol. 
2004;172(5):3252-9.

The allergen immuntherapy and biomarker field.

21. KleinJan A, McEuen AR, Dijkstra MD, Buckley MG, Walls AF, Fokkens WJ. Basophil and eosinophil accumulation and mast cell degranulation in the nasal mucosa of patients with hay fever after local allergen provocation. J Allergy Clin Immunol. 2000;106(4):677-86.

22. Klaewsongkram J, Ruxrungtham $K$, Wannakrairot $P$, Ruangvejvorachai P, Phanupak P. Eosinophil count in nasal mucosa is more suitable than the number of ICAM-1-positive nasal epithelial cells to evaluate the severity of house dust mite-sensitive allergic rhinitis: a clinical correlation study. Int Arch Allergy Immunol. 2003;132(1):68-75.

23.• Lao-Araya M, Steveling E, Scadding GW, Durham SR, Shamji MH. Seasonal increases in peripheral innate lymphoid type 2 cells are inhibited by subcutaneous grass pollen immunotherapy. J Allergy Clin Immunol. 2014;134(5):1193-5 e4.

The allergen immuntherapy and biomarker field.

24. Taher YA, Henricks PA, van Oosterhout AJ. Allergenspecific subcutaneous immunotherapy in allergic asthma: immunologic mechanisms and improvement. Libyan J Med. 2010;5:5303.

25. Wambre E, DeLong JH, James EA, LaFond RE, Robinson D, Kwok WW. Differentiation stage determines pathologic and protective allergen-specific CD4+ T-cell outcomes during specific immunotherapy. J Allergy Clin Immunol. 2012;129(2):544-51-551.e1-7.

The allergen immuntherapy and biomarker field.

26. Novak N. Targeting dendritic cells in allergen immunotherapy. Immunol Allergy Clin North Am. 2006;26(2):307-19. viii

27. Akdis CA, Akdis M. Mechanisms of allergen-specific immunotherapy and immune tolerance to allergens. World Allergy Organ J. 2015;8(1):17.

28. Shamji MH, Durham SR. Mechanisms of immunotherapy to aeroallergens. Clin Exp Allergy. 2011;41(9):1235-46.

29. Eifan AO, Shamji MH, Durham SR. Long-term clinical and immunological effects of allergen immunotherapy. Curr Opin Allergy Clin Immunol. 2011;11(6):586-93.

30. Kappen JH, Durham SR, Veen HI, Shamji MH. Applications and mechanisms of immunotherapy in allergic rhinitis and asthma. Ther Adv Respir Dis. 2017;11(1):73-86.

31. Matsuoka T, Shamji MH, Durham SR. Allergen immunotherapy and tolerance. Allergol Int. 2013;62(4):403-13.

32. Spits H, Cupedo T. Innate lymphoid cells: emerging insights in development, lineage relationships, and function. Annu Rev Immunol. 2012;30:647-75

33. Artis D, Spits H. The biology of innate lymphoid cells. Nature. 2015;517(7534):293-301.

34. Imai Y, Yasuda K, Sakaguchi Y, Haneda T, Mizutani H, Yoshimoto T, et al. Skin-specific expression of IL-33 activates group 2 innate lymphoid cells and elicits atopic dermatitis-like inflammation in mice. Proc Natl Acad Sci U S A. 2013;110(34):13921-6.

35. Hams E, Locksley RM, McKenzie AN, Fallon PG. Cutting edge: IL-25 elicits innate lymphoid type 2 and type II NKT cells that regulate obesity in mice. J Immunol. 2013;191(11):5349-53.

36. Kim BS, Siracusa MC, Saenz SA, Noti M, Monticelli LA, Sonnenberg GF, et al. TSLP elicits IL-33-independent innate lymphoid cell responses to promote skin inflammation. Sci Transl Med. 2013;5(170):170ra16.

37. Salimi M, Barlow JL, Saunders SP, Xue L, GutowskaOwsiak D, Wang X, et al. A role for IL-25 and IL-33driven type- 2 innate lymphoid cells in atopic dermatitis. J Exp Med. 2013;210d:2939-50.

38. Doherty TA, Scott D, Walford HH, Khorram N, Lund S, Baum R, et al. Allergen challenge in allergic rhinitis rapidly induces increased peripheral blood type 2 innate lymphoid cells that express CD84. J Allergy Clin Immunol. 2014;133(4):1203-5.

The allergen immuntherapy and biomarker field.

39. Lombardi V, Beuraud C, Neukirch C, Moussu H, Morizur L, Horiot S, et al. Circulating innate lymphoid cells are differentially regulated in allergic and nonallergic subjects. J Allergy Clin Immunol. 2016;138(1):305-8.

40.• Gueguen C, Bouley J, Moussu H, Luce S, Duchateau M, Chamot-Rooke J, et al. Changes in markers associated with dendritic cells driving the differentiation of either $\mathrm{TH} 2$ cells or regulatory T cells correlate with clinical benefit during allergen immunotherapy. J Allergy Clin Immunol. 2016;137(2):545-58.

The allergen immuntherapy and biomarker field.

41. Zimmer A, Bouley J, Le Mignon M, Pliquet E, Horiot S, Turfkruyer $M$, et al. A regulatory dendritic cell signature correlates with the clinical efficacy of allergen-specific sublingual immunotherapy. J Allergy Clin Immunol. 2012;129(4):1020-30.

42. Zissler UM, Esser-von Bieren J, Jakwerth CA, Chaker AM, Schmidt-Weber CB. Current and future biomarkers in allergic asthma. Allergy. 2016;71(4):475-94.

43. Sakaguchi S, Yamaguchi T, Nomura T, Ono M. Regulatory $\mathrm{T}$ cells and immune tolerance. Cell. 2008;133(5):775-87.

44. Suarez-Fueyo A, Ramos T, Galan A, Jimeno L, Wurtzen PA, Marin A, et al. Grass tablet sublingual immunotherapy downregulates the TH2 cytokine response followed by regulatory T-cell generation. J Allergy Clin Immunol. 2014;133(1):130-8 e1-2.

45. Radulovic S, Jacobson MR, Durham SR, Nouri-Aria KT. Grass pollen immunotherapy induces Foxp3expressing CD4+ CD25+ cells in the nasal mucosa. J Allergy Clin Immunol. 2008;121(6):1467-72-72 e1.

46.• van de Veen W, Stanic B, Yaman G, Wawrzyniak M, Sollner S, Akdis DG, et al. IgG4 production is confined to human IL-10-producing regulatory B cells that suppress antigen-specific immune responses. J Allergy Clin Immunol. 2013;131(4):1204-12.

The allergen immuntherapy and biomarker field. 
47. $\quad$ Mauri C, Bosma A. Immune regulatory function of B cells. Annu Rev Immunol. 2012;30:221-41.

The allergen immuntherapy and biomarker field.

48. Jutel M, Jaeger L, Suck R, Meyer H, Fiebig H, Cromwell O. Allergen-specific immunotherapy with recombinant grass pollen allergens. J Allergy Clin Immunol. 2005;116(3):608-13.

49. Reisinger J, Horak F, Pauli G, van Hage M, Cromwell O, Konig F, et al. Allergen-specific nasal IgG antibodies induced by vaccination with genetically modified allergens are associated with reduced nasal allergen sensitivity. J Allergy Clin Immunol. 2005;116(2):347-54.

50. Gomez E, Fernandez TD, Dona I, Rondon C, Campo P, Gomez F, et al. Initial immunological changes as predictors for House Dust Mite immunotherapy response. Clin Exp Allergy. 2015;45(10):1542-53.

51. Gehlhar K, Schlaak M, Becker WM, Bufe A. Monitoring allergen immunotherapy of pollen-allergic patients: the ratio of allergen-specific IgG4 to IgG1 correlates with clinical outcome. Clinical and Experimental Allergy. 1999;29(4):497-506.

The allergen immuntherapy and biomarker field.

52. Moverare R, Elfman L, Vesterinen E, Metso T, Haahtela T. Development of new IgE specificities to allergenic components in birch pollen extract during specific immunotherapy studied with immunoblotting and Pharmacia CAP System. Allergy. 2002;57(5):423-30.

53. Nelson HS, Nolte H, Creticos P, Maloney J, Wu JM, Bernstein DI. Efficacy and safety of timothy grass allergy immunotherapy tablet treatment in North American adults. J Allergy Clin Immun. 2011;127(1):72-U138.

54. $\quad$ van Neerven RJ, Knol EF, Ejrnaes A, Wurtzen PA. IgEmediated allergen presentation and blocking antibodies: regulation of T-cell activation in allergy. Int Arch Allergy Immunol. 2006;141(2):119-29.

The allergen immuntherapy and biomarker field.
55.• James LK, Shamji MH, Walker SM, Wilson DR, Wachholz PA, Francis JN, et al. Long-term tolerance after allergen immunotherapy is accompanied by selective persistence of blocking antibodies. J Allergy Clin Immunol. 2011;127(2):509-16 e1-5.

The allergen immuntherapy and biomarker field.

56. Ishizaka T, De Bernardo R, Tomioka H, Lichtenstein LM, Ishizaka K. Identification of basophil granulocytes as a site of allergic histamine release. Journal of immunology. 1972;108(4):1000-8.

57. Schroeder JT, Kagey-Sobotka A, Lichtenstein LM. The role of the basophil in allergic inflammation. Allergy. 1995;50(6):463-72.

58. MacGlashan Jr D. Expression of CD203c and CD63 in human basophils: relationship to differential regulation of piecemeal and anaphylactic degranulation processes. Clinical and experimental allergy : journal of the British Society for Allergy and Clinical Immunology. 2010;40(9):1365-77.

59. Buhring HJ, Streble A, Valent P. The basophil-specific ectoenzyme E-NPP3 (CD203c) as a marker for cell activation and allergy diagnosis. Int Arch Allergy Immunol. 2004;133(4):317-29.

60. Knol EF, Mul FP, Jansen H, Calafat J, Roos D. Monitoring human basophil activation via CD63 monoclonal antibody 435. J Allergy Clin Immunol. 1991;88(3 Pt 1):328-38.

The allergen immuntherapy and biomarker field.

61. Casale TB, Wood D, Richerson HB, Trapp S, Metzger WJ, Zavala D, et al. Elevated bronchoalveolar lavage fluid histamine levels in allergic asthmatics are associated with methacholine bronchial hyperresponsiveness. J Clin Invest. 1987;79(4):1197-203. 